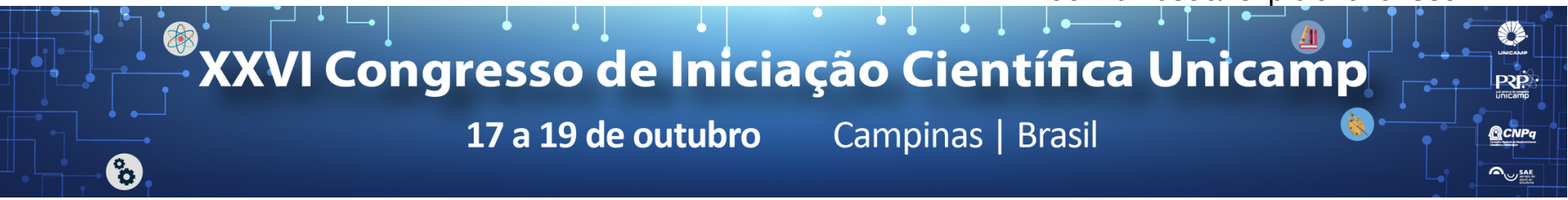

\title{
Atenção visual para sistemas robóticos com Deep Learning
}

\section{Erik de Godoy Perillo*, Esther Luna Colombini}

\section{Resumo}

Deteç̧ão de regiões salientes é componente fundamental da nossa visão. Neste projeto, estendemos trabalhos anteriores e introduzimos uma rede convolucional eficiente para detecção de saliência em imagens e colocamos componentes que melhoram seu desempenho em vídeo.

\section{Palavras-chave:}

Deep Learning, Robótica, Atenção Visual.

\section{Introdução}

Um componente fundamental para que formas de vida complexas interajam de forma eficiente com o ambiente é a habilidade de dar foco apenas ao relevante, evitando assim o processamento desnecessário de enormes quantias de dados ${ }^{1}$.

A atenção é um processo que faz parte do dia a dia de diversos seres vivos em diversas maneiras e é razoável inspirar-se nela para a construção de mecanismos semelhantes para a construção de sistemas de inteligência artificial em máquinas.

Em trabalhos anteriores, foi desenvolvido um modelo de saliência visual com uma rede neural convolucional eficiente. A arquitetura da rede permitiu que fossem atingidos resultados comparáveis ao estado da arte, com um número de parâmetros reduzido em $75 \%$. Neste trabalho, objetivamos construir um modelo de saliência visual com arquitetura ainda mais leve e também eficiente para vídeo.

\section{Resultados e Discussão}

Baseando-se em trabalhos anteriores, foi desenvolvida uma rede neural convolucional com encoder e decoder, no estilo de redes Unet. A entrada são imagens no espaço de cor LAB e a saída são os mapas de saliência ${ }^{2}$. Treinou-se em 15000 imagens do dataset SALICON. A figura 1 ilustra a rede. Para detecção de saliência em vídeos, são necessários ajustes. Seres vivos não mantêm o foco visual fixo em um componente do que veem, mas o foco muda com o tempo por um processo conhecido por Inhibition of Return (IOR), que basicamente torna mais difícil focar em áreas já muito focadas com o passar do tempo. O IOR foi aplicado por meio de um ajuste no mapa de saliência de saída produzido pela rede. É calculado um mapa de IOR e o mapa final do tempo $t+1$ é dado por:

com

$$
S_{t+1}=R_{t+1} * I O R_{t+1}
$$

$$
I O R_{t+1}=\frac{k_{p} P(t)+k_{i} I(t)+k_{d} D(t)+k_{c} C}{k_{p}+k_{i}+k_{d}+k_{c}}
$$

e o cálculo de cada mapa proporcional, integrativo e derivativo ilustrado na figura 2. Comparou-se 0 desempenho no dataset SAVAM de saliência em vídeo.

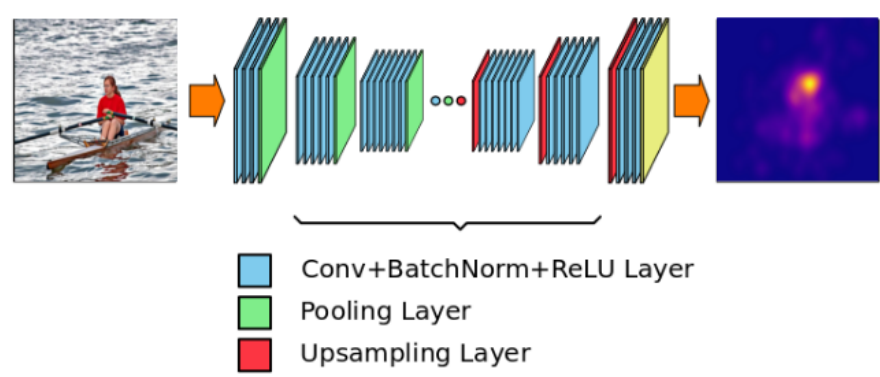

Figura 1. llustração da arquitetura de rede neural usada no trabalho.

$$
\begin{gathered}
P(t)=1-S_{t} \\
I(t)=\frac{1}{1+\int_{0}^{t} S_{\tau} d \tau} \\
D(t)=\left(1+\left.S^{\prime}(x)\right|_{x=t}\right) / 2
\end{gathered}
$$

Figura 2. Equações dos mapas intermediários de IOR.

Tabela 1. Comparação de desempenho do modelo estático e com IOR no dataset SAVAM.

\begin{tabular}{|c|c|c|}
\hline Modelo & Métrica & Valor \\
\hline Estático & CC & 0.41 \\
\hline Estático & SIM & 0.37 \\
\hline Estático & MSE & 0.40 \\
\hline Estático + IOR & CC & $\mathbf{0 . 4 6}$ \\
\hline Estático + IOR & SIM & $\mathbf{0 . 4 1}$ \\
\hline Estático + IOR & MSE & $\mathbf{0 . 1 1}$ \\
\hline
\end{tabular}

\section{Conclusão}

Neste trabalho, desenvolvemos uma rede convolucional eficiente para detecção de saliência visual e foi adicionada uma extensão para vídeos que melhorou o desempenho.

\section{Agradecimentos}

Agradecemos ao CNPq pelo fomento à pesquisa.

${ }^{1}$ Treisman, A. M.; Gelade, G. A feature-integration theory of attention. 1980. ${ }^{3}$ Frintrop, S. VOCUS: a visual attention system for object detection and goaldirected search. 2005. 